\title{
TECNOLOGIAS DIGITAIS NA ÁREA DE MATEMÁTICA DA POLÍTICA EDUCACIONAL DA BNCC: REFLEXÕES PARA O ENSINO FUNDAMENTAL
}

\author{
DIGITAL TECHNOLOGIES IN THE MATHEMATICS AREA OF BNCC'S EDUCATIONAL \\ POLICY: REFLECTIONS FOR ELEMENTARY EDUCATION
}

\author{
Nilce Fátima Scheffer ${ }^{1}$, Gabriela Finn², Mateus Henrique Zeiser ${ }^{3}$
}

Recebido: abril/2020 Aprovado: maio/2020

\begin{abstract}
Resumo: Este artigo apresenta dados e reflexões de pesquisa, referente à área de Matemática do Ensino Fundamental - Anos Finais, do discurso presente no texto da Política Educacional - Base Nacional Comum Curricular - BNCC, sob a perspectiva das tecnologias digitais para ressignificar o ensino. Um breve histórico de políticas educacionais é apresentado a fim de contextualizar a implementação da BNCC. A pesquisa baseia-se na coleta qualitativa de dados, analisando o conteúdo e aspectos formais presentes no discurso escrito, no sentido, na retórica e nas palavras do documento da BNCC, considerando a prática matemática com tecnologias digitais, o pensamento computacional e objetos de aprendizagem. Os resultados obtidos até o momento demonstram que na BNCC as tecnologias digitais ainda estão relacionadas de forma tímida com os conhecimentos matemáticos analisados nas áreas temáticas da base, dada a referência ao assunto presente no discurso de seu texto. Problemas como a formação dos educadores, o planejamento e a necessidade de novas práticas docentes são abordados, uma vez que podem contribuir para a compreensão, a visualização e a representação no ensino de Matemática. Dessa maneira, concluímos que é preciso cobrar políticas educacionais capazes de dar conta dessas necessidades que a nova realidade nos impõe.
\end{abstract}

Palavras-chave: política educacional da BNCC; tecnologias digitais na educação; políticas educacionais; educação básica; ensino de matemática; objetos de aprendizagem.

\begin{abstract}
This article presents data and research reflections, referring to the area of Mathematics of Elementary School - Final Years, at discourse present in the Educational Policy text - National Common Curricular Base - NCCB, from the perspective of digital technologies to give new meaning to teaching. A brief history of educational policies is presented in order to contextualize the implementation of the NCCB. The research is based on qualitative data collection, analyzing the content and formal aspects present in the written discourse, in the sense, in the rhetoric and in the words of the NCCB document, considering the mathematical practice with digital technologies, computational thinking and learning objects. The results obtained so far demonstrate that at NCCB digital technologies are still timidly related to the mathematical knowledge analyzed in the thematic areas of the base, given the reference to the subject present in the discourse of its text. Problems such as educator training, planning and the need for new teaching practices are addressed, as it can contribute to understanding, visualization and representation in the teaching of Mathematics. Thus, we conclude that it is necessary to demand educational policies capable of meeting these needs that the new reality imposes on us.
\end{abstract}

Keywords: NCCB educational policy, digital technologies in education, educational policies, basic education, math teaching, learning objects.

1 iD 000-0001-9199-9750 - Doutora em Educação Matemática - UNESP, Professora da UFFS - Campus de Chapecó SC Brasil. Av. Fernando Machado 685D, Ap. 505, Centro, CEP 89802.111, Chapecó SC, Brasil. E-mail: nilce.scheffer@uffs.edu.br

2 0000-0002-1915-4224 - Mestranda em Educação - UFFS- Campus de Chapecó SC Brasil. Av. Fernando Machado 685D, Ap. 505, Centro, CEP 89802.111, Chapecó SC, Brasil.E-mail: gabifinn94@gmail.com

3 (iD 0000-0002-0861-2218 - Graduando em Matemática - UFSS-Campus de Chapecó SC Brasil. Av. Fernando Machado 685D, Ap. 505, Centro, CEP 89802.111, Chapecó SC, Brasil.E-mail: mateushenriquezeiser@outlook.com 


\section{Introdução}

Este texto contempla uma investigação relativa ao discurso presente no texto da Base Nacional Comum Curricular - BNCC, considerando a presença de tecnologias digitais no ensino de Matemática do Ensino Fundamental - Anos Finais, no âmbito da reflexão atual estabelecida para a prática pedagógica em documentos oficiais, estudo documental (BARDIN, 2016; MORAES; GALIAZZI, 2016; MORAES, 1999; FIORENTINI; LORENZATO, 2012).

Para a coleta de dados, foram considerados os aspectos formais presentes no discurso do texto, buscando uma análise da retórica presente no texto da BNCC, de abordagem qualitativa, utilizando-se da categorização e da análise de conteúdo de Bardin (2016) para a constituição dos dados e resultados. Volta-se também para considerações a respeito da prática pedagógica com tecnologias digitais, com destaque para o pensamento computacional presente na educação matemática e nas construções matemáticas.

No Brasil, a partir da década de 80 , as políticas educacionais se voltaram à incorporação das tecnologias digitais para o ambiente escolar, apresentando-as como contribuição aos processos de ensinar e de aprender. Neste artigo, nos propomos a apresentar uma reflexão quanto às políticas educacionais brasileiras voltadas à inserção das tecnologias digitais e delinear a sua presença na área de matemática prevista no documento da BNCC para o Ensino Fundamental - Anos Finais.

No estudo, assumimos uma postura teórica que compreende a utilização das tecnologias digitais, nos ambientes educacionais, como possibilidade de desenvolvimento do estudante em suas diferentes linguagens, o que pode ocorrer com o acesso a tecnologias informáticas e seu uso nas aulas de matemática. Por essa razão, este artigo está constituído de três partes, que contemplam as Políticas Educacionais e as tecnologias digitais; as tecnologias digitais e a formação dos professores no contexto educacional; o estudo - caminhos metodológicos - e a apresentação de um recorte dos dados e resultados.

\section{Políticas Educacionais e Tecnologias Digitais}

Nesta pesquisa, voltamos nosso olhar às políticas públicas inseridas no campo da educação, porque abordam e contemplam ações propostas para o ambiente e a comunidade escolar. A partir da redemocratização do Brasil e da implementação da Constituição Federal de 1988 , mudanças ocorreram no campo das políticas educacionais, em especial com a aprovação da Lei de Diretrizes e Bases da Educação Nacional (LDB - Lei n. ${ }^{\circ}$ 9.394/96); a aprovação da Emenda Constitucional que instituiu o Fundo de Manutenção e Desenvolvimento do Ensino Fundamental (FUNDEF - Lei n. ${ }^{\circ}$ 9.424/96); e a aprovação do Plano Nacional de Educação (PNE Lei . $\left.^{\circ} 10.172 / 2001\right)$.

Para Mainardes, Ferreira e Tello (2011), a pesquisa em políticas educacionais vem se configurando no Brasil como um campo distinto e em busca de consolidação, motivo pelo qual os pesquisadores sugerem a discussão de referenciais teórico-metodológicos das pesquisas que têm sido desenvolvidas para a análise de políticas. Assim, para os autores, o processo de 
formulação de políticas é considerado como um ciclo contínuo, no qual as políticas são formuladas e recriadas.

Desse modo, Draibe (2001), quando se refere à avaliação de implementação de políticas públicas, enfatiza que o esboço de uma metodologia de trabalho em políticas públicas envolve as pesquisas de avaliações que respondem também a objetivos de verificação de eficácia, de eficiência e de prestação de conta das ações, aspectos que contribuem para que a implementação delas ocorra de modo satisfatório.

Por outro lado, Dourado (2007) destaca que, infelizmente, no Brasil a constituição das políticas educacionais não é contínua, uma vez que é comum evidenciar políticas de governo em desfavor de políticas de Estado, resultando em deficiência e pouco êxito nas mudanças pedagógicas dos sistemas de ensino.

$\mathrm{Na}$ educação brasileira, a história da informática teve sua origem na década de 70 e, a partir daí, muitos programas foram implementados, destacando os projetos EDUCOM, FORMAR e Um Computador por Aluno - UCA, o Programa Nacional de Informática Educativa - Proninfe, o Programa Nacional de Informática na Educação - Prolnfo (hoje Prolnfo Integrado), inspirados pela ideia de mudanças pedagógicas com o uso do computador (VALENTE; ALMEIDA, 1997; ALMEIDA, 2008; CARDOSO; FIGUEIRA-SAMPAIO, 2019), objetivando informatizar a escola e possibilitar diferentes propostas pedagógicas.

Atualmente, o Plano Nacional de Educação - PNE (2014-2024) aponta para o desenvolvimento de aspectos tecnológicos e intenciona "incentivar o desenvolvimento, selecionar, certificar e divulgar tecnologias educacionais para a educação infantil, o ensino fundamental e o ensino médio e incentivar práticas pedagógicas inovadoras que assegurem a melhoria do fluxo escolar e aprendizagem" (BRASIL, 2014, p. 16).

A BNCC, aprovada em 2018, tornou-se uma "referência nacional para [...] os currículos dos sistemas e das redes escolares dos Estados, do Distrito Federal, dos Municípios e das propostas pedagógicas das instituições escolares" (BRASIL, 2018, p. 8). Apresentada em três grupos específicos - Educação Infantil, Ensino Fundamental (anos iniciais e anos finais) e Ensino Médio - tem as etapas do Ensino Fundamental e Médio divididas por áreas de conhecimento.

Consequentemente, neste momento, a BNCC - que é a política em avaliação no estudo é entendida como um documento responsável por orientar, também, a inclusão das tecnologias digitais e o debate relacionado ao pensamento computacional na educação básica. Assim, as análises textuais se concentraram em caminhos apresentados na Base e concebidos "como aspectos fundamentais a fazerem parte de ações para o ensino nas escolas brasileiras nos próximos anos" (FINN; SCHEFFER, 2020, p. 9).

\section{As tecnologias digitais e a formação dos professores no contexto educacional}

A pesquisa busca analisar o conteúdo, aspectos formais presentes no discurso da BNCC, considerando a retórica do documento com relação ao uso de tecnologias digitais no ensino e na aprendizagem da matemática. Para Moraes (1999, p. 8), a análise de conteúdo constitui uma 
metodologia de pesquisa usada para descrever e interpretar o conteúdo de toda classe de documentos e textos. Essa análise, conduzindo a descrições sistemáticas, qualitativas ou quantitativas, ajuda a reinterpretar as mensagens e a atingir uma compreensão de seus significados num nível que vai além de uma leitura comum.

Kenski (2012) destaca que os computadores eram vistos com desconfiança e como modismo, sendo usados de maneira aplicada e afastados do cenário escolar. Entretanto, no decorrer dos anos essa perspectiva foi sendo alterada e as tecnologias digitais passaram a fazer parte do cenário escolar.

Assim como aconteceu com diferentes práticas comunicativas, como a oralidade e a escrita, a prática das tecnologias digitais começou a ganhar maior visibilidade e a fazer parte da vida da maioria dos estudantes. Para Lütchemeyer e Scheffer (2011) e Scheffer (2015, p. 81), as tecnologias já deixaram de ser modismo e fazem parte das necessidades básicas do profissional e da vida das pessoas, o que implica novas atitudes humanas e exige um outro perfil do indivíduo, principalmente dos profissionais da educação, possibilitando aos educandos novos ambientes para a construção de conhecimentos.

Essa introdução das tecnologias digitais nas escolas pode transformar as práticas educativas, proporcionando novos métodos de aprendizagem que resultam em ambientes mais interativos e dinâmicos (SCHEFFER e HEINECK,2016). Para que isso venha a ocorrer é necessário haver planejamento nas redes de ensino considerando as especificidades dos estabelecimentos e preparo por parte dos docentes, concebendo o computador como aliado na relação com o ensino (ABREU e BAIRRAL, 2010, p. 23).

A partir do olhar dos autores, esse avanço das tecnologias digitais poderá resultar em uma reestruturação do sistema escolar, o que possivelmente mudará a dinâmica das aulas. Uma manifestação disso está no planejamento das políticas públicas onde essa preocupação e a busca de possíveis soluções se apresenta, tal como a BNCC. De todo modo, essa nova posição educacional possibilita uma interação entre professor e estudante, conduzindo para uma forma de aprendizagem mais dinâmica, que também promove reflexões matemáticas para os estudantes.

O documento coloca em destaque a necessidade de desenvolver o pensamento computacional, que pode ser adquirido com a aprendizagem matemática, conforme o texto da Base:

A aprendizagem de Álgebra, como também aquelas relacionadas a outros campos da Matemática (Números, Geometria e Probabilidade e Estatística), podem contribuir para o desenvolvimento do pensamento computacional dos alunos, tendo em vista que eles precisam ser capazes de traduzir uma situação dada em outras linguagens, como transformar situações-problema, apresentadas em língua materna, em fórmulas, tabelas e gráficos e vice-versa (BRASIL, 2018, p. 266).

Diante de tal perspectiva, Finn e Scheffer (2020) consideram que o pensamento computacional trabalha com o abstrato, com a redução de problemas em subpartes, contando ou não com as tecnologias digitais, o que é semelhante com o que a BNCC busca em sua proposta 
para o ensino de matemática nos anos finais do Ensino Fundamental. Desse modo, a visualização e a manipulação das tecnologias digitais enriquecem a abordagem de conceitos matemáticos, pode-se concluir que a BNCC, contém um discurso que incentiva o estudante na busca da experimentação de problemas para uma melhor compreensão da área, consolidando os significados e conceitos matemáticos.

Para Barbosa e Maltempi, (2020), o pensamento computacional consiste numa competência e/ou habilidade a ser desenvolvida durante processos de ensino de conteúdos da matemática. Por essa razão, afirmam que, ao trabalhar determinadas estratégias de aprendizagem da matemática como resolução de problemas, investigação e modelagem matemática, cria-se um ambiente rico para se desenvolver competências relacionadas ao letramento matemático e, também, ao pensamento computacional. Esses autores consideram o pensamento computacional como uma abordagem para a resolução de problemas, capaz de projetar sistemas e compreender o comportamento humano que se baseia em conceitos da ciência da computação, atribuindo a ele a mesma importância de habilidades básicas, como ler, escrever e calcular.

Diante disso concebe-se o pensamento computacional em matemática, neste estudo, como uma capacidade a ser desenvolvida, na escola, nos processos de ensino e de aprendizagem que promovem a resolução de problemas e habilidades investigativas.

\section{0 estudo - caminhos metodológicos}

Este estudo é de caráter qualitativo e a coleta de dados baseia-se na análise documental, "[...] desenvolvida através da discussão que os temas e os dados suscitam" (SÁ-SILVA; ALMEIDA; GUINDANI, 2009, p. 11). A organização de dados é realizada a partir da análise de conteúdo, que, de acordo com Bardin (2016), é um conjunto de técnicas e procedimentos de análise, seu conteúdo, suas significações - explícitas ou ocultas - e ocorre em três fases: pré-análise; exploração do material; e tratamento dos resultados, inferência e interpretação.

Moraes (1999, p. 3 e 4) coloca em destaque, como método de investigação, a análise de conteúdo, que compreende procedimentos especiais para o processamento de dados científicos. É uma ferramenta, um guia prático para a ação, sempre renovada em função dos problemas cada vez mais diversificados que se propõe a investigar. Segundo o autor, a matériaprima da análise de conteúdo pode constituir-se de qualquer material oriundo de comunicação verbal ou não verbal, como cartas, cartazes, jornais, revistas, informes, livros, relatos autobiográficos, discos, gravações, entrevistas, diários pessoais, filmes, fotografias, vídeos. Os dados advindos dessas diversificadas fontes chegam ao investigador em estado bruto, necessitando ser processados para facilitar o trabalho de compreensão, interpretação e inferência a que aspira a análise de conteúdo.

Consequentemente, para Moraes (1999 p. 9), a categorização é, portanto, uma operação de classificação dos elementos de uma mensagem seguindo determinados critérios. Ela facilita a análise da informação, mas deve fundamentar-se numa definição precisa do problema, dos objetivos e dos elementos utilizados na análise de conteúdo. 
Neste estudo, assume-se também a Análise Textual Discursiva, que, segundo Moraes e Galiazzi (2016), assume pressupostos que a localizam entre a Análise de Conteúdo e a Análise de Discurso. Assim, esse tipo de análise pode tanto se inserir num, como em outro desses movimentos, pois a análise qualitativa tem preocupações descritivas e interpretativas.

A partir desse aporte metodológico, o estudo investiga a discussão presente na BNCC da área de matemática, em relação à prática pedagógica e às tecnologias digitais, no Ensino Fundamental - Anos Finais. A coleta de dados teve por objetivo uma análise e compreensão do sentido que a tecnologia digital tem para a BNCC no ensino de matemática do 6 - ao 9 o ano do Ensino Fundamental - Anos Finais.

Inicialmente, para apresentar os dados da pesquisa que conduzirão a categorização, organizamos um quadro elaborado para quantificar a presença de expressões no texto da BNCC, que remetem às tecnologias digitais nas grandes áreas da matemática. Esse quadro foi dividido por ano escolar e unidades temáticas de matemática.

$\mathrm{Na}$ análise, o discurso presente no texto da Base foi interpretado considerando o sentido das palavras, com uma busca por relações entre as propostas para cada unidade temática, tecnologias digitais e objetos de aprendizagem. Para a quantificação, descrição e análise, foram levadas em conta as habilidades, que foram o principal foco das palavras e dos seus significados no texto.

\section{Alguns resultados em discussão}

A partir da análise da BNCC, observa-se que, nas competências específicas da matemática, há citações referentes às tecnologias digitais em dois momentos, como na primeira e quinta competência:

1. Reconhecer que a Matemática é uma ciência humana, fruto das necessidades e preocupações de diferentes culturas, em diferentes momentos históricos, e é uma ciência viva, que contribui para solucionar problemas científicos e tecnológicos e para alicerçar descobertas e construções, inclusive com impactos no mundo do trabalho.

5. Utilizar processos e ferramentas matemáticas, inclusive tecnologias digitais disponíveis, para modelar e resolver problemas cotidianos, sociais e de outras áreas de conhecimento, validando estratégias e resultados (BRASIL, 2018, p. 263).

Na primeira competência específica da área da matemática para o Ensino Fundamental Anos Finais, o documento refere-se a uma aplicação da matemática no mundo do trabalho, enfatizando diferentes culturas e períodos da história. Também considera a matemática como uma ciência viva, que pode se apoiar nas tecnologias digitais para descobrir novas formas de ensino.

Já na quinta competência, a BNCC coloca as tecnologias digitais como um meio de modelar, modificar a maneira de pensar e construir conceitos matemáticos, objetivando a resolução de problemas do dia a dia que não necessariamente sejam matemáticos. 
Assim, para iniciarmos nossa discussão, como ponto de partida da análise da BNCC se tem uma real dimensão da preferência do documento em utilizar as tecnologias digitais em cada uma das Unidades Temáticas previstas para a matemática por ano escolar. Neste momento, apresentamos a quantificação de alguns dados no Quadro 1, para iniciar uma discussão a respeito das habilidades específicas de cada área da matemática, do 6으 ao 9ㅇao, e da presença ou não das tecnologias digitais previstas para o ensino de matemática, quantificação essa que nos remeterá ao processo de categorização.

Quadro 1 - Frequência quantitativa de termos voltados para tecnologias digitais, por ano escolar e unidade temática da Matemática na BNCC.

\begin{tabular}{|c|c|c|c|c|}
\hline \multirow{2}{*}{$\begin{array}{l}\text { Unidade } \\
\text { temática }\end{array}$} & \multicolumn{4}{|c|}{ Ano Escolar } \\
\hline & 60 ano & 70 ano & 80 ano & 9o ano \\
\hline Números & Calculadora (4) & Calculadora (1) & $\begin{array}{l}\text { Tecnologias } \\
\text { Digitais (1) }\end{array}$ & $\begin{array}{l}\text { Tecnologias } \\
\text { Digitais (1) }\end{array}$ \\
\hline Álgebra & $\begin{array}{l}\text { Nenhuma } \\
\text { expressão }\end{array}$ & $\begin{array}{l}\text { Nenhuma } \\
\text { expressão }\end{array}$ & $\begin{array}{c}\text { Tecnologias } \\
\text { (1) }\end{array}$ & $\begin{array}{l}\text { Nenhuma } \\
\text { expressão }\end{array}$ \\
\hline Geometria & $\begin{array}{l}\text { Softwares (2) } \\
\text { Tecnologias } \\
\text { digitais (1) }\end{array}$ & Softwares (2) & Softwares (2) & Softwares (2) \\
\hline $\begin{array}{c}\text { Grandezas e } \\
\text { Medidas }\end{array}$ & $\begin{array}{l}\text { Tecnologias } \\
\text { digitais (1) }\end{array}$ & $\begin{array}{l}\text { Nenhuma } \\
\text { expressão }\end{array}$ & $\begin{array}{l}\text { Nenhuma } \\
\text { expressão }\end{array}$ & $\begin{array}{l}\text { Informática (1) } \\
\text { Computadores (1) }\end{array}$ \\
\hline $\begin{array}{c}\text { Probabilidade } \\
\text { e Estatística }\end{array}$ & $\begin{array}{l}\text { Planilhas } \\
\text { eletrônicas (1) }\end{array}$ & $\begin{array}{l}\text { Planilhas } \\
\text { eletrônicas (1) }\end{array}$ & $\begin{array}{l}\text { Nenhuma } \\
\text { expressão }\end{array}$ & $\begin{array}{c}\text { Planilhas } \\
\text { eletrônicas (2) }\end{array}$ \\
\hline
\end{tabular}

Fonte: Os autores/dados da pesquisa, 2021.

A partir do Quadro 1, constata-se que a presença das tecnologias digitais predomina com expressões e termos como softwares e planilhas eletrônicas, que aparecem nas áreas temáticas de Geometria e Probabilidade e Estatística e calculadora na unidade temática Números. No caminho oposto, são utilizadas as expressões tecnologias digitais, que aparecem nas unidades temáticas de Números e Grandezas e Medidas. Os termos informática e computadores aparecem uma vez em cada unidade temática Grandezas e Medidas, assim como a palavra tecnologias aparece na unidade temática Álgebra.

Há predominância da palavra software na Unidade Temática de Geometria, aspecto que pode ser justificado pela contribuição que a representação e a visualização apresentam, graças ao uso de softwares. Nessa perspectiva, Duval (2012) defende que a geometria necessita da representação e visualização, o que pode contribuir com a compreensão, e que somente dessa forma os objetos matemáticos podem ser entendidos. 
Ainda se observa que na área de Geometria há 8 aparições de termos que remetem às tecnologias digitais, enquanto que na unidade temática de Números possui 7 aparições, o que a coloca como a segunda colocada. E com apenas 4 aparições de termos está a Unidade Temática de Probabilidade e Estatística. Na área de Grandezas e Medidas são 3 aparições e a área de Álgebra possui a menor quantidade de aparições, com somente uma vez a palavra tecnologia, quando ainda se tem uma dúvida de ela se referir a algo digital ou não, pois o documento não especifica.

Desse modo, pode-se observar aspectos do Pensamento Computacional com a abordagem da resolução de problemas, com o compreender do comportamento humano, atribuindo a ele a mesma importância de habilidades básicas como ler, escrever e calcular (BARBOSA e MALTEMPI, 2020).

\section{Categorizando: as tecnologias digitais e a BNCC}

Para o processo de categorização, estaremos considerando a segunda fase, prevista por Bardin (2016), que é a exploração do material, caracterizada pela aplicação sistemática das decisões tomadas na fase anterior, a qual consiste na codificação, decomposição e enumeração dos dados, tendo em vista as regras já formuladas; e, ainda, a terceira fase, que é o tratamento dos resultados, inferência e interpretação. Nesta última fase, os resultados são tratados para que se tornem significativos e válidos, permitindo assim construir quadros, figuras, diagramas que representem as informações obtidas pela análise.

Nesse sentido, a seguir apresenta-se uma breve discussão a respeito de três Unidades Temáticas da área de Matemática, no que tange às tecnologias digitais presentes no texto da Base.

Na Unidade Temática de Números, a BNCC coloca as tecnologias digitais como um recurso didático no cálculo de porcentagens, principalmente nos cálculos envolvendo números irracionais, em que com o auxílio digital se obtém mais precisão. Esse exercício contribuirá na aprendizagem da matemática. Por sua vez, a experiência com os números irracionais nos meios digitais, como softwares, também pode contribuir no processo de desenvolvimento do pensamento numérico, como pode-se observar no trecho abaixo:

Os alunos devem dominar também o cálculo de porcentagem, porcentagem de porcentagem, juros, descontos e acréscimos, incluindo o uso de tecnologias digitais (BRASIL, 2018, p. 265).

Na Unidade Temática de Álgebra, a BNCC promove uma relação entre o processo de cálculos envolvendo incógnitas e o desenvolvimento do pensamento computacional, uma vez que os problemas algébricos estão postos, na maioria das vezes, de maneira genérica e, segundo o documento,

Outra habilidade relativa à álgebra que mantém estreita relação com o pensamento computacional é a identificação de padrões para se estabelecer generalizações, propriedades e algoritmos (BRASIL, 2018, p. 267). 
Como visto na BNCC, as tecnologias digitais contribuem para a compreensão matemática, podendo ser usadas na representação de grandezas, como números e medidas, além de auxiliarem na resolução de problemas algébricos e na representação e visualização de figuras geométricas. Assim, de acordo com Finn e Scheffer (2020), a visualização, a partir da manipulação que as tecnologias digitais proporcionam, enriquece a abordagem de conceitos matemáticos, além de incentivar o estudante na busca da experimentação de problemas.

Na Unidade Temática de Geometria, a BNCC, nas habilidades previstas para o 8 o ano, incentiva o uso de softwares para auxiliar na discussão e construção geométrica, facilitando a representação e visualização desses objetos matemáticos, conforme podemos observar:

1- Objeto de conhecimento: Construções geométricas: ângulos de $90^{\circ}, 60^{\circ}, 45^{\circ}$ e $30^{\circ}$ e polígonos regulares.

Habilidade: (EFO8MA15) Construir, utilizando instrumentos de desenho ou softwares de geometria dinâmica, mediatriz, bissetriz, ângulos de $90^{\circ}, 60^{\circ}, 45^{\circ}$ e $30^{\circ}$ e polígonos regulares.

2- Objeto de conhecimento: Transformações geométricas: simetrias de translação, reflexão e rotação.

Habilidade: (EFO8MA18) Reconhecer e construir figuras obtidas por composições de transformações geométricas (translação, reflexão e rotação), com o uso de instrumentos de desenho ou de softwares de geometria dinâmica (BRASIL, 2018, p. 315, grifo nosso).

Na habilidade (EF08MA15), o documento incentiva o uso de softwares de geometria dinâmica para construir lugares geométricos. Já na habilidade (EF08MA18), o uso de softwares de geometria dinâmica pode contribuir para a representação e visualização das figuras que são obtidas da manipulação de transformações geométricas.

Nessa perspectiva, o uso de softwares de geometria dinâmica no ensino de matemática pode possibilitar também a investigação e a experimentação, como Dias evidencia:

A utilização de softwares de geometria dinâmica no ensino e aprendizagem de Geometria tanto pode ser mais uma ilustração para a aula como um rico material didático que instiga a curiosidade dos alunos e aguça seu espírito investigativo, levando-os a elaborar conjecturas sobre situações diversas (2009, p. 49).

Outra opção identificada com a leitura do documento diz respeito aos objetos virtuais de aprendizagem, que, segundo Borges e Scheffer (2018), podem ser obtidos através de fotos, vídeos ou com o software do GeoGebra, por exemplo. Esses objetos podem facilitar o entendimento geométrico com a possibilidade que oferecem para visualizar e representar figuras.

Nesse contexto, o agente responsável por reorganizar o processo de ensino e de aprendizagem com as tecnologias digitais é o professor. Esse aspecto de mudança na prática pedagógica vem a ser confirmado por Kenski (2012, p. 45), quando nos diz que, por mais que as escolas usem computadores e Internet em suas aulas, estas continuam sendo seriadas, finitas 
no tempo, definidas no espaço restrito das salas de aula de aprofundamento dos conhecimentos em áreas específicas do saber.

Ou seja, as tecnologias digitais devem fazer a diferença e estimular os estudantes a verem sentido em seu uso. Assim, para obtermos mudanças que influenciem os processos de ensino e de aprendizagem com as tecnologias digitais, o professor precisa refletir sobre suas vantagens e limitações e incorporá-las em suas práticas sempre que possível.

Sob tal ótica e considerando as reflexões estabelecidas nesta categoria, pode-se destacar os processos de ensino e de aprendizagem conforme previstos na BNCC, para os anos finais do Ensino Fundamental, como algo que, na esteira dessa posição epistemológica, permite entender a Matemática como uma ciência exata que procura expressar, objetivamente e por linguagem própria, os fenômenos da natureza (FREITAS et. al, 2019).

\section{Considerações reflexivas}

Para concluir, cabe dizer que ainda existem aspectos a serem ajustados e melhorados para que as tecnologias digitais, de fato, façam parte das práticas pedagógicas. Como vimos, o documento da BNCC sugere o uso de tecnologias digitais para desenvolver conceitos matemáticos em todas as unidades temáticas da matemática. Destacamos os softwares de geometria dinâmica para desenvolver as habilidades de construção e transformação de figuras geométricas, como um recurso didático no cálculo de porcentagens, principalmente nos cálculos envolvendo números irracionais com mais precisão, o que pode contribuir também no processo de desenvolvimento do pensamento numérico e algébrico, no Ensino Fundamental.

Porém, apenas um documento não assegura que as tecnologias digitais farão parte das práticas dos professores. Para que as transformações pedagógicas sejam alcançadas, precisamos investir em formações de professores, para que sejam capazes de superar as dificuldades encontradas em relação às tecnologias digitais e os conhecimentos matemáticos.

Nesse sentido, a partir da nossa Interpretação para a BNCC, de que é uma política educacional e manifesta em seu texto a valorização da inserção das tecnologias digitais na Educação Básica, além de propiciar uma real dimensão da importância dos meios digitais nos dias atuais, permite vislumbrar que a formação dos professores deve ocorrer num processo contínuo, para que os mesmos, se sintam encorajados a inserir tais recursos na prática docente.

Nesta ótica, Finn e Scheffer (2020, p. 130) evidenciam que as práticas pedagógicas, uma vez que introduzidas no meio digital, potencializam a participação e a aprendizagem dos estudantes; entretanto, para que essa prática ocorra, todos os agentes envolvidos precisam se adaptar às mudanças. Desse modo, a partir da análise do discurso (Moraes e Galiazzi, 2007), presente no texto da BNCC, pode-se dizer que a introdução das tecnologias digitais nas Unidades Temáticas da matemática, conforme contemplados no seu texto, alcançam uma inserção ainda tímida em relação à frequência de aparições.

Por outro lado, mesmo que timidamente, o documento da BNCC põe em destaque uma profunda inovação para a educação brasileira, trazendo consigo novas perspectivas de auxílio educacional, que abrangem as tecnologias digitais, habilidades e competências a serem 
consideradas para o ensino de matemática e o pensamento computacional. Esses são os aspectos considerados quando se referem ao planejamento necessário do professor para alcançar a proposta de documentos oficiais, de modo que envolvam as escolas em toda a rede de ensino, considerando-se as singularidades e o contexto de cada local (ABREU e BAIRRAL, 2010; BARBOSA e BAIRRAL, 2018; BONOTTO e GIOVELI 2018; SCHEFFER, SPERANDIO e BATTISTI, 2021; OLIVEIRA, CANAVARRO E MENEZES, 2021; RICHIT, 2021).

Consequentemente, o professor deve fazer escolhas que agreguem as tecnologias digitais nos processos de ensino e de aprendizagem matemática, de maneira que potencializem novas experiências. Nesse contexto, vale considerar posições que confirmam que o trabalho em sala de aula fica mais significativo quando conta com a diversidade proporcionada pelas tecnologias digitais, aquecidas pelas discussões, debates e conflitos gerados, aspecto que parece ser um desafio para os professores que delas farão uso em sua docência (SCHEFFER, 2015, 2017 e SCHEFFER, COMACHIO, CENCI e HEINECK 2018).

\section{Referências}

ABREU, P. F. e BAIRRAL, M. A. O uso que professores de matemática fazem da informática educativa em suas aulas. In: BAIRRAL, Marcelo Almeida (org.). Tecnologias informáticas, salas de aula e aprendizagens matemáticas. Rio de Janeiro: Edur, 2010.

ALMEIDA, M. E. B. Educação e tecnologias no Brasil e em Portugal em três momentos de sua história. Educação, Formação \& Tecnologias, v. 1(1), p. 23-36, 2008.

BARBOSA, R. C. e BAIRRAL, M. A. Algumas reflexões de Licenciandos em Matemática sobre materiais curriculares educativos on-line, In SCHEFFER, N. F.; COMACHIO, E. CENCI, D. (Org.). Tecnologias da Informação e Comunicação na Educação Matemática: articulação entre pesquisas, objetos de aprendizagem e representações. Curitiba, PR: CRV, 2018, p. 97-116.

BARBOSA, L. L. S.; MALTEMPI, M. V., Matemática, Pensamento Computacional e BNCC: desafios e potencialidades dos projetos de ensino e das tecnologias na formação inicial de professores. RBECM, Passo Fundo, v. 3, n. 3, p. 748-776, ed. espec. 2020.

BARDIN, L. Análise de conteúdo: edição revista e ampliada. São Paulo: Edições 70, 2016.

BONOTTO, D. L. e GIOVELI, I., Professores que ensinam matemática em formação continuada: relações entre o trabalho docente e o GeoGebra, In SCHEFFER, N. F.; COMACHIO, E.; CENCI, D. (Org.). Tecnologias da Informação e Comunicação na Educação Matemática: articulação entre pesquisas, objetos de aprendizagem e representações. Curitiba, PR: CRV, 2018, p. 149 - 166.

BORGES, P. A. e SCHEFFER, N.F., Contribuições de Objetos virtuais para a aprendizagem de conceitos de geometria, In SCHEFFER, N. F.; COMACHIO, E.; CENCI, D. (Org.). Tecnologias da Informação e Comunicação na Educação Matemática: articulação entre pesquisas, objetos de aprendizagem e representações. Curitiba, PR: CRV, 2018, p. 63-78.

BRASIL, Ministério da Educação. Aprova o Plano Nacional de Educação. Lei n.ำ 13.005, de 25 de junho de 2014. 
BRASIL. Ministério da Educação. Base Nacional Comum Curricular. 2018. Disponível em: http://basenacionalcomum.mec.gov.br/download-da-bncc. Acesso em: 10 fev. 2021.

CARDOSO, M. C. S. A.; FIGUEIRA-SAMPAIO, A. S. Dificuldades para o uso da informática no ensino: percepção dos professores de matemática após 40 anos da inserção digital no contexto educacional brasileiro. Educ. Matem. Pesq., São Paulo, v. 21, n. 2, p. 44-84, 2019.

DIAS, M. S. S. Um estudo de demonstração no contexto da licenciatura em matemática: uma articulação entre os tipos de prova e os níveis de raciocínio geométrico. (Tese Doutorado em Educação Matemática) - Pontifícia Universidade Católica de São Paulo. São Paulo, 2009.

DOURADO, L. F. Políticas e gestão da Educação Básica no Brasil: limites e perspectivas. Educação \& Sociedade, Campinas: v. 28, n. 100, p. 921-946, 2007.

DRAIBE, S. Avaliação de implementação: esboço de uma metodologia de trabalho em políticas públicas. In: BARREIRA. M. C. R. N., CARVALHO, M. C. B. (Org.). Tendências e perspectivas na avaliação de políticas e programas sociais. São Paulo: IEE/PUC-SP, 2001.

DUVAL, R. Registros de representação semiótica e funcionamento cognitivo do pensamento. Tradução: Méricles Tadeu Moretti, REVEMAT, Florianópolis SC, V.7 n.2 p. 266-297.2012.

FREITAS, F. M.; BERTOLUCCI, C. C.; ROVEDA, C. A.; SILVA J. A. Abrindo a caixa de pandora: as competências da Matemática na BNCC. RPEM, Campo Mourão, PR, v. 8, n. 17, p. 265-291, jul.dez. 2019. https://doi.org/10.33871/22385800.2019.8.17.265-291.

FINN, G.; SCHEFFER, N. F. As políticas educacionais e tecnologias digitais na matemática, EMSF Revista Educação Matemática Sem Fronteiras, Chapecó, SC, v. 2 n. 2 (2020), p. 113-133.

FIORENTINI, D.; LORENZATO, S. Investigações em educação matemática: percursos teóricos e metodológicos. Campinas, SP: Autores Associados, 2012.

KENSKI, V. M. Educação e tecnologias: o novo ritmo da informação. 8. ed. Campinas, SP: Papirus, 2012.

LÜTCHEMEYER, R. R.; SCHEFFER, N. F. Objetos de aprendizagem na construção do conceito de logaritmos. In: ENCITEC - Ensino de Ciências e Tecnologia em Revista. Santo Ângelo, RS. v. 1, n. 2, p. 1-6, jul./dez. 2011.

MAINARDES, J.; FERREIRA, M.; TELLO, C. Análise de políticas: fundamentos e principais debates teórico-metodológicos. In: Políticas Educacionais: questões e dilemas. São Paulo: Cortez, 2011. p. 143-172.

MORAES, R. Análise de conteúdo. Revista Educação, Porto Alegre, v. 22, n. 37, p. 7-32, 1999.

MORAES, R.; GALIAZZI, M. C. Análise textual discursiva. ljuí: Unijuí, 2016.

OLIVEIRA, H., CANAVARRO, A. P., e MENEZES, L. Desenvolver novas perspectivas sobre o ensino de matemática através da análise da prática: os casos de multimédia na formação de professores. In RICHIT A.OLIVEIRA H. (Orgs), Formação de professores e tecnologias Digitais. São Paulo: Livraria da Física, 2021. p. 117-142 
RICHIT, A. Tecnologias Digitais na formação de professores dos anos iniciais. In RICHIT A.OLIVEIRA H. (Orgs), Formação de professores e tecnologias Digitais. São Paulo: Livraria da Física, 2021. p. $63-88$

SÁ-SILVA, J. R.; ALMEIDA, C. D.; GUINDANI, J. F. Pesquisa documental: pistas teóricas e metodológicas. Revista Brasileira de História \& Ciências Sociais, Ano I, n. I, p. 1-15, 2009.

SCHEFFER, N. F. As TIC na formação do professor de Matemática: um olhar para a investigação de conceitos geométricos. In: LOSS, A. S.; CAETANO, A. P. V.; PONTE, J. P. P. (Org.). Formação de professores no Brasil e em Portugal: pesquisas, debates e práticas. Curitiba, PR: Appris, 2015. p. 273-288.

SCHEFFER, N. F.; HEINECK, A. E. Ambientes Informatizados de Aprendizagem na investigação de construções geométricas: uma experiência com professores do Oeste Catarinense. Caminho Aberto - Revista de Extensão do IFSC, SC ano 3, n. 4, p. 16-22, jul. 2016.

SCHEFFER, N. F. Tecnologias digitais e representação matemática de movimentos corporais. Curitiba, PR: Appris, 2017.

SCHEFFER, N. F.; COMACHIO, E. CENCI, D. HEINECK, A. Uma interação com Objetos virtuais de Aprendizagem na discussão de conceitos geométricos In SCHEFFER, N. F.; COMACHIO, E. CENCI, D. (Org.). Tecnologias da Informação e Comunicação na Educação Matemática: articulação entre pesquisas, objetos de aprendizagem e representações. Curitiba, PR: CRV, 2018, p. 97-116.

SCHEFFER, N. F., SPERANDIO P. e BATTISTI, S. Tecnologias Digitais e Políticas de Formação de Professores. In RICHIT A.OLIVEIRA H. (Org), Formação de professores e tecnologias Digitais. São Paulo: Livraria da Física, 2021. p. 143 -166.

VALENTE, J. A.; ALMEIDA, F. J. Visão Analítica da Informática no Brasil: a questão da formação do professor. Revista Brasileira de Informática na Educação-SBIE, n. 1, p. 1-28. 1997. 